\title{
Motorcycle Related Ocular Injuries In Irrua Specialist Teaching Hospital, Irrua, Edo State, Nigeria.
}

\author{
${ }^{1}$ Dr M E Enock, ${ }^{2}$ Dr O A Dawodu, ${ }^{3}$ Dr A I Osahon
}

\begin{abstract}
This is a prospective study of all cases of motorcycle related accidents with involvement of the eyes seen at the Irrua Specialist Teaching Hospital from January 2005 to December 2005.

The study was conducted to assess the severity of ocular trauma, ocular structures mostly affected and initial effect on visual acuity in such injuries.

All cases referred to the eye clinic as well as cases presenting at the Accident and Emergency Unit of the Hospital with eye trauma, with or without other associated injuries from motorcycle accidents were included (even if not referred to the Eye Clinic).

Fifty-six patients were seen. There were forty seven males (84\%) and nine females (16\%). The predominant age group was 21-30 years. Those mostly affected were students (14.1\%). Ten patients had associated head injury with or without fracture of the facial bones. Two patients had fracture of the femur. The lids, conjuctiva and cornea were the ocular structures mostly affected.

The use of protective helmets with facial covering for all motorcyclists should be enforced. Job creation for unemployed youths will make earning a living as commercial motorcyclists less attractive. Provision of good mass transportation system and an improvement in the road network will abolish the need for the use of motorcycle as a means for public transportation.
\end{abstract}

\section{INTRODUCTION}

Motorcycles have recently become a major means of transportation both in Urban and Rural parts of Nigeria and some other

KEYwORDS: Motorcycles, Ocular injuries

Departments Ophthalmologist, Irrua Specialist Teaching Hospital, Irrua, Edo State, Nigeria, Department of Consultant Ophthalmologist, University of Benin Teaching Hospital, PMB 1111, Benin City.

Correspondence Author: Dr. M. E Enock, Dr. O. A. Dawodu, Dr. A. I. Osahon Consultant Ophthalmologist, Irrua Specialist Teaching Hospital, Irrua, Edo State, Nigeria, Consultant Ophthalmologist, University of Benin Teaching Hospital, PMB 1111, Benin City. developing countries. This is because of its ability to meander through traffic congestion and also ply inadequately maintained earth roads more easily than cars and buses ${ }^{1}$.

As opposed to developed countries where the rider as well as the passenger on a motorcycle are required to wear safety helmets by law, this has not been successfully enforced in Nigeria even though the legislation provides for it.

Poor enforcement of licensing regulations has also allowed room for some rider who have not had the mandatory eye 
test, and riding proficiency tested, to obtain licenses. As a result, many motorcycle riders are ignorant of the Highway Code. This situation has resulted in the frequent occurrence of accidents between motor vehicles and motorcyclist, motorcyclist and pedestrians as well as between motorcyclists.

These accidents are sometimes fatal with severe injuries to various parts of the body.

This study was aimed at finding out ocular injuries that resulted from motorcycle accidents over a one-year period, January to December, 2005.

\section{METHODOLOGY}

All cases referred to the Eye Clinic of Irrua Specialist Teaching Hospital, Irrua, as a result of motorcycle accidents were included. Also, cases of eye injuries occurring in patients seen at the Accident and Emergency Unit of the Hospital occurring alone or co-existing with head injury from motorcycle accidents were included even if they were not referred to the eye clinic.

Visual acuity was measured with Snellen's chart in those who were conscious. Eye examination was done with the aid of a pen torch, slit lamp biomicroscope and direct Ophthalmoscope.

The age, sex and presenting complaints were noted. The type of ocular trauma was documented. Any co-existing trauma in other parts of the body was also noted. We ascertained if the patient was a motorcyclist or a passenger on a motorcycle, previous involvement in motorcycle accident and whether they had a helmet on or not at the time of the accident.

\section{RESULTS}

Fifty-six patients were seen during the period of study. There were forty-seven males (84\%) and nine females (16\%). The age and sex distribution is as shown on Table Most of the patients involved were aged between 21-30 years (52\%). The least affected age group was under 10 years (1.8\%). Of the nine females who had ocular injury, eight of them were passengers, only one was a rider. Most of the riders were males (forty seven.

Table 2 shows the occupation of the patients with ocular injury from motorcycle accidents. Majority were students (41.1\%). This is probably due to the fact that the students of the Ambrose Alli University (A.A.U), which is about $8 \mathrm{~km}$ from the Hospital, use motorcycles as a major means of transportation to and from their hostels which are mostly located outside the University campus. Only twelve of the riders (21.4\%) were commercial motorcyclists.

Table 3 shows the types of ocular trauma. Involvement of the conjunctiva either in form of traumatic conjunctivitis, subconjunctival haemorrhage or conjunctival laceration was the commonest condition seen $(24.1 \%)$. This is followed by lid laceration and corneal lesions either in form of laceration, abrasion or ulceration, contributing $22.8 \%$ each.

Table 4 shows associated injuries. Face and scalp, bruises and laceration were the most common, occurring in $48.4 \%$. This is followed by those with head injuries and fractures of bones of the face $(32.2 \%$.).

The visual acuity on presentation is shown on table 5 . Over twenty eight percent (28.6\%) of the eyes were blind by WHO definition (Visual acuity of less that 3/60.) About a third of the eyes had visual acuity between $6 / 9$ and $6 / 12$. Approximately $20 \%$ of the eyes had normal visual acuity.

None of the patients was wearing a helmet at the time of the accident. Only two of the commercial motorcyclists agreed to having had previous motorcycle accidents. Of these, one has had two previous accidents.

Thirty one out of the 56 patients (55.4\%) who sustained ocular trauma had other con-existing non-ocular trauma. 
26 Journal of Medicine and Biomedical Research

Table 1 Age and Sex Distribution of Patients with Ocular Trauma

\begin{tabular}{lllll}
\hline Age (years) & Male & Female & Total & Percentages \\
\hline Below 10 years & 1 & 0 & 1 & 1.8 \\
$10-20$ & 3 & 1 & 4 & 7.1 \\
$21-30$ & 25 & 4 & 29 & 51.8 \\
$31-40$ & 8 & 0 & 8 & 14.3 \\
$41-50$ & 6 & 1 & 7 & 12.5 \\
$51-60$ & 2 & 1 & 3 & 5.3 \\
$61-70$ & 2 & 0 & 2 & 3.6 \\
Above 70 years & 0 & 2 & 2 & 3.6 \\
\hline Total & 47 & 9 & 56 & 100
\end{tabular}

Table 2 Occupation and Sex Distribution of Patients

\begin{tabular}{lclll}
\hline & Occupation & Male & Female & Total \\
\hline Percentage Students/Pupils & 18 & 5 & 23 & 41.1 \\
Commercial Motorcyclists & 12 & 0 & 12 & 21.4 \\
Businessmen/Women & 3 & 2 & 5 & 8.9 \\
Others & 3 & 2 & 5 & 8.9 \\
\hline Total & 47 & 9 & 56 & 100
\end{tabular}

Table 3 Types of Ocular Trauma

\begin{tabular}{lll}
\hline Types of Ocular Trauma & Number of Eyes & Percentage \\
\hline Conjunctivitis, subconjunctival haemorrhage laceration & 19 & 24.1 \\
Lid laceration & 18 & 22.8 \\
Corneal laceration/abrasion/ulceration & 18 & 22.8 \\
Conjunctival/Corneal foreign body & 3 & 3.8 \\
Hypopyon & 3 & 3.8 \\
Hyphaema & 3 & 3.8 \\
Iritis & 5. & 6.3 \\
Cataract/Lens Subluxation & 4 & 5.0 \\
Vitreous haemorrh & 3 & 3.8 \\
Opticage atrophy & 13 & 3.88 \\
\hline Total & 79 & 100
\end{tabular}

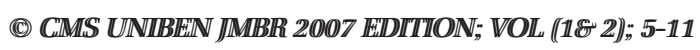


Table 4 Coexisting non-ocular trauma.

\begin{tabular}{lllll}
\hline Types of injury & Male & Female & Total & Percentages \\
\hline Face and scalp of bruises/laceration & 13 & 2 & 15 & 84.4 \\
Head injury and facial fractures & 8 & 2 & 10 & 32.2 \\
Fracture of the long bones & 5 & 1 & 6 & 19.4 \\
\hline Total & 26 & 5 & 31 & 100
\end{tabular}

Table 5 Visual Acuity at presentation in the affected Eye

\begin{tabular}{lllll}
\hline Visual Acuity in affected Eye & Male & Female & Total & Percentages \\
\hline $6 / 6$ or better & 7 & 4 & 11 & 19.6 \\
$6 / 12-6 / 9$ & 17 & 0 & 17 & 30.4 \\
$6 / 36-6 / 18$ & 10 & 0 & 10 & 17.8 \\
CF $>3 \mathrm{M}-6 / 60$ & 1 & 1 & 2 & 3.6 \\
NLP $>$ CF $<3 \mathrm{M}$ & 12 & 4 & 16 & 28.6 \\
\hline Total & 47 & 9 & 56 & 100 \\
\hline
\end{tabular}

\section{DISCUSSION}

Ocular trauma has been shown to be one of the major causes of mono-ocular visual loss, low vision and blindness worldwide with sig n if i c a n t s o c i o-e c o n o m i c consequences. ${ }^{2}$

A lot of changes have taken place in our environment in recent times. Population growth, apparent financial empowerment and availability of imported used vehicles without a commensurate development of mass transport system has resulted in astronomical increase in the number of vehicles on our roads. ${ }^{1}$ Motorcycles have also become a major means of transportation in Nigeria and some developing countries. ${ }^{8,9}$ Unfortunately, there is no corresponding increase in road networking. ${ }^{10}$ Even the existing roads are not adequately maintained, resulting in traffic congestion with attendant risk to road users resulting in road traffic accidents. $^{8,10}$

Reliance on motorcycles as a means of transportation and also for earning a living has also increased markedly in the last decade in Nigeria due to lack of gainful employment opportunities. This factor has resulted in university graduates and undergraduates using motorcycles for commercial purposes so as to earn a living or support themselves at school.

The male to female ratio of 5.2:1 shows a clear male predominance as in previous reported cases of ocular trauma. ${ }^{11,12,13,14,15}$ This is due to the fact that commercial motorcycle riders are mainly men. The peak age 
incidence shows that most commercial motorcycle riders are mainly young men (21 30 years of age.)

The conjunctiva, eyelids and cornea were the eye structures mostly affected. This is expected because of the anterior location of the structures. ${ }^{2,15}$ Involvement of the conjunctiva either in form of traumatic conjunctivitis, subconjunctival haemorrhage or conjunctival laceration was the most common condition seen. Corneal laceration, abrasion or ulceration and lid laceration were the next commonest type of ocular injury recorded. This again is not surprising because most motorcycle riders and passengers do not wear protective goggles.

Ten patients had associated head injury with or without fracture of facial bones (zygomatic complex, mandibular or maxillary bones fracture.) Fifteen patients also had facial and scalp bruises or laceration, In all, therefore, twenty-five patients had associated injuries involving the head. None of the patients involved in the accidents was wearing protective helmet at the time of the accident.

The three cases that had hypopyon also had corneal ulcer. Also, the three cases that had traumatic hyphaema were the same that had optic atrophy due largely to secondary glaucoma.

These group of patients did not present on time and usually would have consulted patent medicine dealers, chemists or general practitioners before coming to the hospital. Some of them had even resorted into using native medication prior presentation. The harmful effect of traditional eye medications (TEM) has been documented. ${ }^{16}$

In conclusion, ocular injuries secondary to motorcycle accidents are becoming more common in Nigeria. The government should therefore, through the law enforcement agents begin to enforce the legislation on the use of protective helmet by motorcycle riders as well as the passengers. In order to facilitate this, motorcycle merchants should be made to include the cost of two helmets when selling a motorcycle. One helmet will be for the motorcyclist and the other for the would be passenger. The marshals or special marshals of the Nigeria Road Safety Corps should begin to arrest and fine motorcycle riders who do not use protective helmets. These helmets should have protective cover over the face, since most motorcycle riders and passengers do not wear protective goggles. The government should also provide good road networks.

In order to reduce proliferation of motorcycles for commercial purposes, the government should embark on measures to improve mass transportation system and the road network. If jobs are provided for the large number of unemployed youths, earning a living, through motorcycle transportation will be less attractive.

Public enlightenment campaigns through electronic media and other means to educate people on the need to seek early and appropriate treatment in cases of ocular injury should also be embarked upon.

\section{References}

1. Osime OC, Ohanaka. EC. Road traffic accidents in a Semi Urban Community in Edo State of Nigeria JMBR 2003; 2(1): 18-24.

2. Omoti AE. Ocular trauma in Benin City. Journal of Trauma 2004; 2:67-71.

3. Elebesunu M. Aetiology of childhood blindness in Benin City Nig J Pub Health 1987; 101(1):59-62.

4. Onwasigwe EN, Onwasigwe CN, Umeh RE. Ocular injury in children. Nigerian Journal of Ophthalmology 1994; 2(2): 9-12

5. Adeoye AO, Olateju SO, Soetan EO. 
Communal conflict related ocular trauma. Nig J Clin Prat 2002; 5(1): 1-4.

6. Umeh RE, Umeh OC. Causes and visual outcome of childhood injuries in Nigeria. Eye 1997; 11(4): 489-495.

7. Otoibhi SC, Osahon AI. Perforating eye injuries in children in Benin City, Nigeria. JMBR 2003; 2(1): 40-45

8. Odelowo EO. Pattern of Pedestrian trauma resulting from motorcycle accidents in Nigeria; a two year prospective study. Afr J Med Sci 1994; 23:109-112

9. Ohanaka EC, Ighedosa SU. Epidemiology of road traffic accidents in Benin City, Nigeria. Nig J Surg Sci 2001; 11:14-18.

10. Odelowo EO. Pattern of Pedestrian injuries from road traffic accidents in Nigeria. W Afr Med J 1992; 11:130-134
11. Macewen CJ. Eye injuries; a prospective survey of 5671 cases. Br J Ophthalmol 1987; 73:888-894

12. Olurin O. Eye injuries in Nigeria. Am J Ophthalmol 1971; 72(1):152-166

13. Abiose A. Eye injuries in Lagos, a review of 157 cases. Nig Med J 1975; 5(2): 105-107

14. Edema OT. Retrospective study of eye injuries. Nig J Surg Sci 1995; 5:63-67

15. Ajaiyeoba AI. Ocular injuries in Ibadan. Nigerian Journal of Ophthalmology. 1995; 3(2): 18-20

16. Osahon AO. Consequences of Traditional eye medication in UBTH, Benin City. Nigerian Journal of Ophthalmology 1995; 3:51-4. 